\title{
Some Challenges Militating against Developing Countries Achieving SDG 4 on Targets: Nigeria as Case Study
}

\author{
Anthony Wakwe Lawrence ${ }^{1 *}$, Noel Ihebuzor ${ }^{2}$, Damiete Onyema Lawrence ${ }^{3}$ \\ ${ }^{1}$ Community Inter-Relations and Conciliation Initiative-CIRCI (Non-Governmental Organization), Port Harcourt, Nigeria \\ ${ }^{2}$ Abuja, Nigeria \\ ${ }^{3}$ Rivers State University, Port Harcourt, Nigeria \\ Email: ^tonylawrence942@gmail.com
}

How to cite this paper: Lawrence, A. W., Ihebuzor, N., \& Lawrence, D. O. (2020). Some Challenges Militating against Developing Countries Achieving SDG 4 on Targets: Nigeria as Case Study. Modern Economy, 11, 1307-1328.

https://doi.org/10.4236/me.2020.117093

Received: June 15, 2020

Accepted: July 18, 2020

Published: July 21, 2020

Copyright $\odot 2020$ by author(s) and Scientific Research Publishing Inc. This work is licensed under the Creative Commons Attribution International License (CC BY 4.0).

http://creativecommons.org/licenses/by/4.0/

\begin{abstract}
The Sustainable Development Goal (SDG) 4, which is "ensuring inclusive and equitable quality education and promoting lifelong learning opportunities for all", is a critical goal that is needed to be achieved for improved quality of life and the developmental advancement of any nation. The United Nations Sustainable Development reports identified some major challenges that can hinder Nigeria from achieving this goal: they include poor funding of education in the budgets, out-of-school-children, prolonged neglect of learning environments and facilities, among many others. We evaluated those identified critical factors of poor funding, poor school enrolment/out-of-school-children and poor school infrastructure using fishbone and problem tree analysis and also applied qualitative descriptive assessment of the 7 SDG 4 targets and the 3 enabling targets. Funding was identified as the key issue and it is also an underlying factor militating against the achievement of many other challenges. The other key challenge of poor school enrolment cannot be resolved with persisting insecurity and Almajiri problems in the northern parts of Nigeria. Without concerted effort to increase the budget for education and ensuring that allocated funds are not misappropriated, it will not be possible to achieve the SDG 4 . This position is reinforced by the fact that Nigeria is currently ranked 159 out of 162 nations in our performance towards achieving the SDGs and also our not too good performance during the Millennium Development Goals (MDGs) era.
\end{abstract}

\section{Keywords}

Poor-Funding, Out-of-School-Children, Sustainable-Development-Goals, Goal-Targets, Descriptive-Assessment, Quality-Education, eLearning 


\section{Introduction}

The international community came together in 2015 and adopted the 17 SDGs as the gold standard which would guide all development and by which all development would henceforth be evaluated. These 17 SDGs were far reaching and touched on virtually all aspects of life in their import and coverage starting from poverty to partnership for development. Sustainable Development Goal (SDG) 4 which reads "Ensuring inclusive and equitable quality education and promoting lifelong learning opportunities for all" is one of these transformative goals of the SDGs and focuses on equitable, inclusive and quality education both as an end but more importantly as dynamo and lever for global development and thus an enabler of the other SDGs.

Education is as old as human existence and the most important in the development of people (Nwachukwu, 2014). Education and continuous innovation have made it possible for humanity to advance from the stone-age to the industrial age and subsequently to the computer/internet age by providing the knowledge, competencies and skills that have led to the emergence of our digital world and the leap frogging of technological innovations and transformations. Our current global economy is a knowledge economy, driven and sustained by education and lifelong learning. Education and research largely allow subsequent endeavors to concentrate on how to improve on current standards in knowledge and technological advancement. Education provides everyone the knowledge to be a better person, to become a global citizen, to express oneself freely without psychological complexes, and to take informed risks. Education describes the process of receiving or giving organized instruction, especially in a formal institution of learning; usually, the school (Marinho, 2002). Scholars now recognize that education can also take place outside of school settings and this type of education is described as informal and non-formal education. Whether it is formal, informal or non-formal, education as a form of socialization is now recognized as the instrument par excellence to drive national development and growth. This is because education arms the recipient with skills, competencies and enables individuals to have the abilities to contribute to the socio-economic transformation of his/her society. Beyond such skills and competencies, education also confers positive transfer effects, known as externalities on societies. Such externalities include a drop in fertility rates, a better capacity to manage the environment in sustainable manners and the emergence of improved civic capacities. It is in recognition of these many benefits of education that development practitioners now see education as central to the attainment of the other SDGs.

There is now growing consensus that progress in the attainment of SDG 4, in meeting its seven targets and its three enablers plays critical roles in the sustainable development of any nation. Such emerging global consensus also underscores the importance of conducting critical analyses of factors in any nation that inhibit the pursuit and attainment of this goal and its target in their totality, as emerging evidence shows that most developing countries, especially in Sub Sa- 
haran Africa are falling behind in their pursuit of SDG 4. Understanding the factors that inhibit the attainment of SDG 4 as well as the interaction of these factors could yield useful insights into the general problems of the implementation of the SDGs in general and more importantly could also provide the basis for informed corrective actions that could propel a defaulting country to higher levels in sustainable development. This study used Nigeria as a case study because Nigeria is the most populous nation in Africa. Nigeria accounts for a very significant population of the African continent and indeed all the developing nations put together. It accounts for $2.64 \%$ of the total world's population (http://www.worldometers.info/, 2019). The proposed study is to analyze these inhibitors to SDG 4 implementation and how they interact in a defined geo-political space, in this case Nigeria, a country that has defined education as an instrument par excellence for accelerating national development is thus a very useful exercise as its spin offs have immediate development relevance and applications to other aspects of development in Nigeria and in most developing nations.

The purpose of this paper is to undertake an analysis of the some of the factors that impede Nigeria's pursuit of SDG 4 using a combination of tools viz fishbone, problem tree and problem descriptive analyses, all graphic tools that have the advantages of revealing links and causalities first do a specific and critical look at some of these key challenges enumerated above (poor funding, out-of-school-children/low enrolment and poor educational infrastructure/facilities). We applied a combination of analytical tools viz fishbone and problem tree analysis of the major identified factors, then qualitative descriptive assessment of the challenges to identify and $x$-ray obstacles and inhibitors to SDG 4 attainment in Nigeria. Such a blend of tools was considered capable of graphical displaying the build-up of problems facing SDG 4 implementation as well as their interconnections. These tools were used to display the failures and gaps that have inhibited the planning, funding and implementation capacities necessary for the delivery of SDG 4. The analysis that is undertaken is informed by data from local sources such the NDHS, MICS, the National Bureau of Statistics, the Education Digest and the National Personnel Audit of the Federal Government and the Universal Basic Education Commission. Data is also obtained from international sources such as UNESCO, UNICEF, the GPE and the World Bank.

\section{Context}

The United Nations (2019) Sustainable Development Goals report highlighted three key areas of SDG 4 challenges: 1) Children and adolescents lack minimum proficiency in reading and mathematics; 2) More than half of the schools in Sub-Sahara Africa do not have access to basic drinking water facilities, internet and computers and 3. 27\% more girls than boys of primary school age are not attending school. Specifically, for Nigeria, the Sustainable Development UN report for Nigeria stated that the key challenge facing Nigeria is Out-Of-School-Children. The report also stated that while $78 \%$ of children in 
the South West can mostly read, only about $17 \%$ of children in the North East can read. The Nigeria 2018 Demographic and Health Survey (NDHS 2019) reports that nearly one third of women in the 15 - 49 age brackets have no education, the gender disparity in access to education who cannot read or write is $22 \%$. Four out of ten women have attended secondary school compared to $48 \%$ of the men. $11 \%$ of women and $17 \%$ of men have more than secondary education and $47 \%$ of women are illiterate compared to $28 \%$ for the men (NDHS, 2019).

The UNICEF report pp3 (2019) further gave more statistics of the following challenges Nigeria has with out of School Children

https://www.unicef.org/nigeria/education:

- Low levels of Early Childhood Education provision as "only 61\% of 6 - 11 year-olds regularly attend primary school and only $35.6 \%$ of children aged 36 - 59 months receive early childhood education".

- Pronounced spatial disparities in the quantity and quality of basic education services with very disturbing manifestations of such disparities in the North East and North West geopolitical zones. Most school aged children in these two zones, especially those residing either in rural areas or in areas of conflict and insurgency do not have access to formal education. As UNICEF (2019) observes "In the north-eastern and north-western states, 29\% and 35\% of Muslim children, respectively, receive Qur'anic education, which does not include basic skills such as literacy and numeracy. The government considers children attending such schools to be officially out-of-schoop".

- Conflict aggravated denial of access to basic education. The UNICEF (2019) report observes that "In north-eastern Nigeria, 2.8 million children are in need of education-in-emergencies support in three conflict-affected States (Borno, Yobe, Adamawa). In these States, at least 802 schools remain closed and 497 classrooms are listed as destroyed, with another 1392 damaged but repairable" (UNICEF, 2019, PP3).

All these are very depressing statistics and indicate Nigeria's major challenges with the pursuit and possible attainment of the target of SDG 4. The other issue noted is that only $1.6 \%$ of GDP is devoted to education. According to UBEC (2019), there are about 10.2 million children out of school children in Nigeria with the states in the northern parts of Nigeria contributing a larger percentage of this case load of out of school children. School infrastructure is mostly in a sad and dismal state with very high pupil to classroom ratio noted in large parts of the country. Pupil-toilet ratio stands at 322 to one toilet, pupil-classroom ratio 1 classroom for 95 pupils. $60 \%$ of schools have no water supply, those with insufficient seating $64 \%$ and schools where classes are held outside due to lack of space is 44\% (EMIS 2018/2019). Pupil to Teacher ratio is also very high and the statistics for pupil to qualified teacher ratio still even higher. For example in one state in the country, qualified teacher/pupil ratio is $1 / 103$, whilst teacher pupil ratio stands at 1/71 (EMIS, 2018/2019). Conditions of service for teachers are very poor and the resulting effect is a highly demotivated teaching force. Learn- 
ing and instructional Materials are in terrible short supply and measures of internal efficiency such as transition, completion and pass rates are also very disturbing. Mathew (2012) equally contributed that Nigeria has a number of challenges that are militating against effective achievement of the SDG 4 goal: inadequate funding; poor infrastructural facilities and poor administration of schools. The latest SDG Ranking by UN assessed Nigeria as the 159 out of 162 nations and it is important that effort is put in place to improve (Global index ranking 2019). These realities are symptomatic of an educational system under stress, and the sources of these stresses are several.

They include problems with funding and also proper utilization of funds for education planning and development (Ololube, 2016). Thus, despite the fact that there have been some arithmetic increases in the budget provision for education, such funding has failed to keep pace with the exponential increase in the population of school aged children being experienced in the country. Other problems include challenges and gaps relating to educational administration and general deficiencies in the instructional system. To enable a richer unpacking of the causes that lead to the unsatisfactory state of affairs in Nigeria's quest to attain SDG 4, a blend of fishbone, problem tree and a qualitative problem descriptive analyses will be applied to unearth our educational challenges.

\section{Literature Review}

This section reviews briefly literature on the implementation of the SDGs plus literature on the two major tools used for this study viz the problem tree and fishbone analysis.

Since the launch of the SDGs in 2015, countries, stakeholders and agencies have been urged to undertake studies that would seek to illuminate challenges involved in the roll out and implementation of these SDGs. Previous studies on challenges of SDG implementation such as Garica et al. (2020) have examined ways different institutions can contribute in the pursuit of the SDGs. Inspired largely by a recognition of the importance of interdisciplinarity and multi-sectoral cooperation in the pursuit of the SDGs, García-Feijo et al. (2020) with specific regard to graduate business schools suggest ways that such institutions can play in accelerating the pursuit of the SDGs by incorporating certain activities. These include "more in-depth actions linked to creating awareness, questioning current paradigms, fostering cooperation and interdisciplinarity with stakeholders, and working on coherence; to more specific interventions such as creating student associations, incorporating new teaching methodologies or increasing students' participation in extracurricular activities" p. 1. One major argument these researchers make which is quite critical to any balanced understanding of the challenges of SDG implementation is the following: "The economic, social and environmental concerns considered in the definition of these 17 objectives can no longer be dealt with in a separate and independent way. These objectives have to be approached in an interdisciplinary way, with all ac- 
tors assuming their share of responsibility (individuals, companies, private and public organizations and institutions, and governments)" p. 2. A major implication for our current study is that SDG 4 though nested in Education cannot be pursued effectively without the cooperation of other ministries, actors and stakeholders. Another interesting implication is the recognition of mutual interactions and influences with SDG 4 for instance influencing and interacting with other SDGs such as SDGs 5, 6, 7 and 8. Another interesting observation from this study is that even the paradigms that are taught in Business schools as central to economic development could have negative externalities on the pursuit of other SDGs thus underscoring the need for paradigm alignment and coherence across and within levels in SDG implementation.

This same problem of interlinkages is also recognised in Allen et al. (2018) who, in addition, prescribe evidence and science-based approaches to SDG implementation with an emphasis on simultaneity, coherence and integration. On the basis of systematic review of SDG implementation literature, Allen et al. (2018) are able to conclude that "while progress has been made in some initial planning stages, key gaps remain in terms of the assessment of interlinkages, trade-offs and synergies between targets. Gaps are also clearly evident in the adoption of systems thinking and integrated analytical approaches and models. This is problematic as it may undermine effective implementation and the transformative potential of the SDGs" (Allen et al. 2018: pp. 1-2). They decry failures and gaps in recognising and applying interlinkages and integration among goals as they recognise the "integrated nature of the goals and targets" and with this the implication that "progress on one goal or target is linked through causal relationships and feedback loops to other goals and targets". They recommend and correctly too, that "an integrated and systems approach to the SDGs is therefore needed to ensure that these feedbacks are understood and managed". Arguing further, they posit that "If mutually reinforcing actions are adopted, and trade-offs between targets minimized, countries will be better placed to deliver on the transformative potential of the 2030 Agenda" (Allen et al. 2018: pp. 1-2). They argue by implication that it is important that countries isolate and focus on high impact and high leverage points as they struggle to implement the SDGs. One implication of this view for the current study is the criticality of causality analysis in identifying and understanding the interactions and synergies between high impact factors as well as high leverage interventions whilst pursuing any SDG and such an observation is valid for the pursuit of SDG 4 if transformational and sustainable change and development are to be achieved here. Causality and fishbone analyses would thus be vital in showing vital links and nexus of interconnections within interventions.

Fishbone diagrams (also called Ishikawa diagrams or cause-and-effect diagrams) are a graphical technique to show the several causes of a specific event or phenomenon. In particular, a fishbone diagram is a common tool used for a cause and effect analysis to identify a complex interplay of causes for a specific 
problem or event. This causal diagram was created by Ishikawa (1990) in the research field of management (Coccia, 2017: p. 4). A fishbone analysis is essentially a Cause and Effect diagram and a very useful tool for finding and significantly identifying the characteristics of work output quality (San, Tijtro, \& Santoso, 2003); Coccia (2018) explained it as an analytical tool used to identify and systematically list the different root causes that can be attributed to a problem. This analysis is called fishbone due to its similarity to a fish, which has a head (As an effect) and a body in the shape of bones, illustrated as causes of known challenges (Tiann, 2012). The Root Cause is the deepest underlying cause(s) of symptoms (either positive or negative) within any process, if resolved would result in the elimination or substantial reduction of the highlighted symptom Preuss (2003). With this, a fishbone diagram facilitates problems or condition's root causes visualization, allowing teams to truly diagnose the difficulty rather than focusing on symptoms. It also permits team members to disconnect a problem's content from its history, allowing mutual agreement around the problem and its causes.

Nevertheless, the Fishbone diagram is limited by the experience of the experts involved and the quality of the results will hinge on persons applying this tool. Secondly, the fishbone does not single out the root cause of the problem because all causes look equally important, efforts can be wasted on recognizing the causes that have little effect on the problem and if the discussion is not controlled one can get an inaccurate result. These observed shortcomings suggest that this type of analysis stands to benefit when complemented by the use of other tools such as the problem tree analysis.

The problem tree is a heuristic that can be best utilized during the initial stage of problem structuring when the analyst faces a complex and vaguely defined problem. For example, the analyst is expected to recommend measures in fields like "youth delinquency", “education” or "unemployment” (Veselý, 2008: p. 68). The problem tree is a universal heuristic for identifying, prioritizing, and visualizing problems. It represents a scheme of problem causes (factors) and effects (consequences). Like every tree, the problem tree has its "stem", "roots", and "branches". Its stem stands for the core problem, its roots are the causes and its branches form the problem's effects P.70. The problem tree should be regarded as a thinking instrument, rather than a final product. It serves more to structure the analytics' and stakeholders' thinking, rather than to provide a definitive or "scientific" position on a problem. It also facilitates initial clarification and structuring of the issue area, rather than modelling relationships (Veselý, 2008). This analysis tool provides at a glance of how a range of complex issues contribute toward a problem and how this problem branches out into a set of consequences (Schiefer \& Döbel, 2001); both causes and consequences are fitted into the diagram on a hierarchical preference basis which takes on a tree shape. The Problem Tree is one method of mapping out core problems, along with their causes and effects, helping project planners identify clear and manageable objectives (Start \& Hovland, 2004). 
By graphically enabling the understanding the core problem and its causes, a problem tree is thus particularly useful for task clarification so vital for effectively dealing with that problem and its effects.

Weiss, Bolton and Shakar (2000) clarified that the analysis method provided in-depth information on the problem, leading to better understanding; which will ensure absolute success through the creation of a multi-pronged strategy to deal with the diverse aspects of the problem. The greatest utility of the problem tree approach thus lies in the way it exposes and details causality as a sequence of hierarchical and interacting factors that must be understood if effective and sustainable problem solution is to be achieved. In reaching a solution based on the results of a causality analysis, proponents insist that if a problem has three causes, all three causes must be treated for that problem to be solved. But these solutions must be sequenced to achieve optimal outcomes.

These two analytical methods (fishbone and problem tree) will be used to deepen our analysis of the challenges facing the implementation of SDG 4 in Nigeria. Insights from the application of these two tools will then be reinforced with the findings from a qualitative descriptive assessment of the problems that are militating against achieving the SDG 4.

\section{Methodology and Findings}

As stated earlier, data that was used to populate the two tools and the descriptive assessment employed in this study were obtained from several sources including National and International Reports and other publications that deals with the analysis and identification of problems of education in Nigeria. The summary of findings from the texts consulted indicate that a number of supply and demand side factors act together to constitute bottlenecks/challenges to the provision of basic education services in Nigeria. These bottlenecks/challenges include inadequate provision of school infrastructure, poor quality of school infrastructure, inadequacy of teaching, insufficiency of teaching force, limited motivation of the teaching force, inadequacy of instructional materials, cost of schooling, inadequacy of funding, faulty fund management, fund misuse, bad school management poor perception of the value of schooling, cultural factors etc. (Marinho, 2002; Ololube, 2016; Nwachukwu, 2014; UBEC report, 2019; UNICEF report 2019). The problem we encountered however was that the identification of these constraints and bottlenecks were merely listings and failed to demonstrate adequately the interactions and mutual influences of these bottlenecks/challenges. To bring such interactions out, the researchers resorted to a deeper level of analysis involving tracing causality and build ups. This phase of the study involved the use of the problem tree, which can be best utilized during the initial stage of problem structuring when the analyst faces a complex and vaguely defined problem (Veselý, 2008) and fishbone analyses by Ishikawa (1990) in the research field of management (Coccia, 2017). A fishbone analysis as stated earlier is a Cause and Effect diagram for finding and identifying the characteristics and sequence of factors/element in work output system and their 
interaction in producing observable results (San, Tijtro, \& Santoso, 2003). Specifically, these two tools were applied to the analysis of the causes and effects of poor funding, low enrolment and poor infrastructure on the pursuit of SDG 4 in Nigeria. The results are presented below.

\subsection{Analysis for Poor Funding}

\subsubsection{The Fishbone Analysis for Poor Funding (Figure 1)}

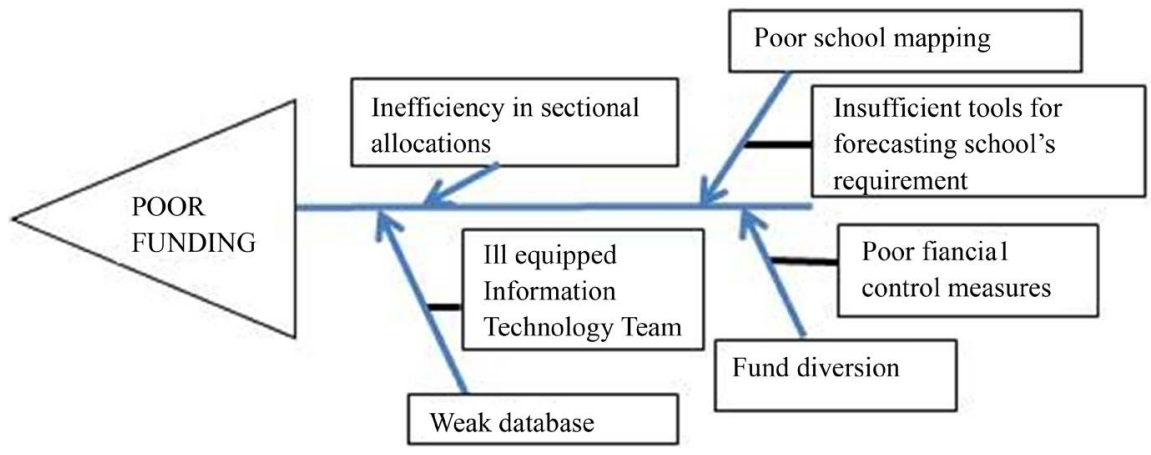

Figure 1. Conceptualized by the researchers.

\subsubsection{The Problem Tree Analysis for Poor Funding (Figure 2)}

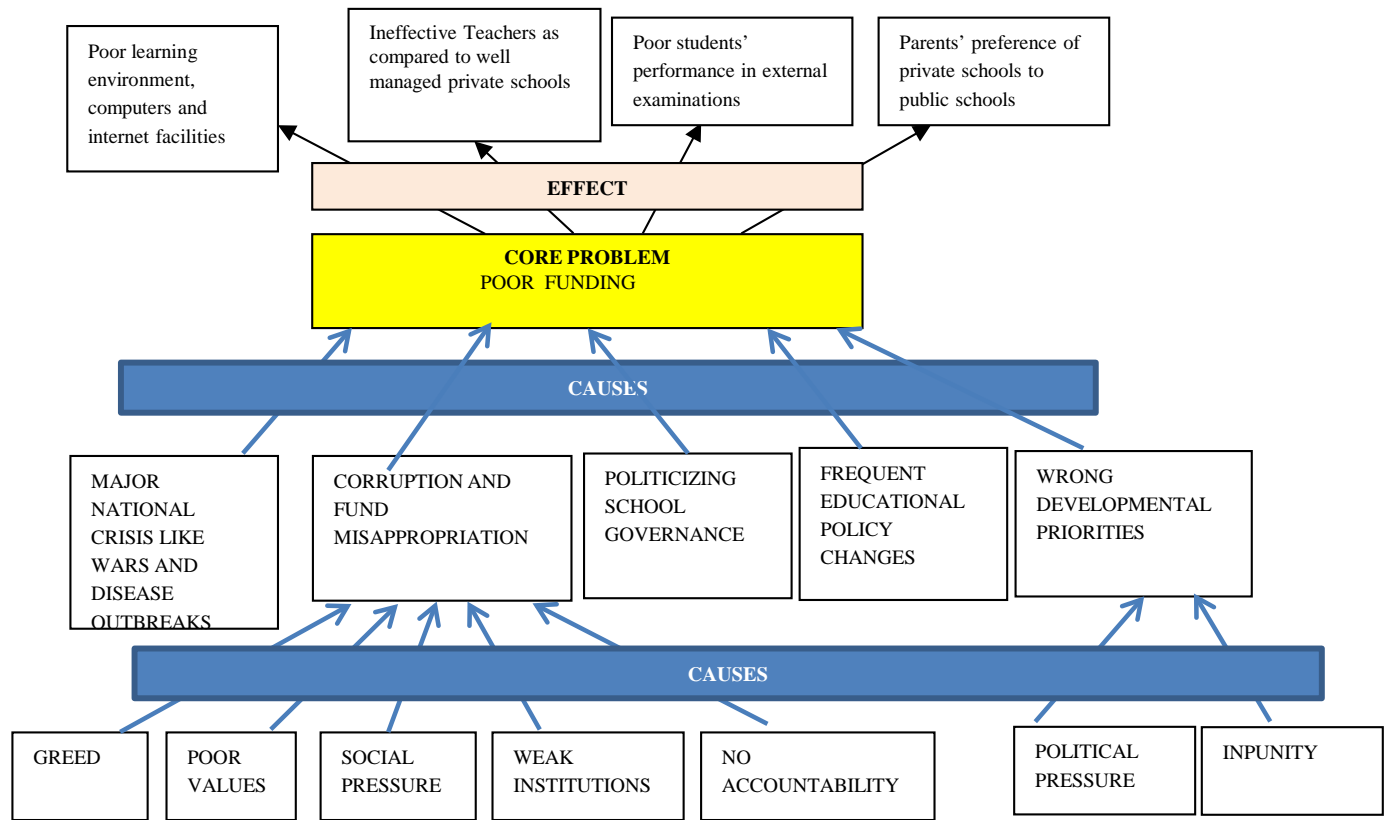

Figure 2. Conceptualized by the researchers.

The problem identified is POOR FUNDING. The identified causes of poor funding in this case are reallocation of funds meant for education to other pressing and urgent areas of managing violent conflicts, epidemic/pandemic disease outbreaks etc, losses/inefficiencies due to corruption/fund misappropriation, wrong prioritization and defunding of education by the political actors for personal areas of interest for political gains, frequent changes in educational 
policies resulting in wastages of previously invested funds and wrong developmental priorities like spending most of the budget on infrastructure instead of encouraging balanced budget that also takes human capital development and education into priority area for attention.

We further drilled down to investigate the causes of corruption/misappropriation of funds and identified causes like greed of the managers, continually degenerating value systems, social pressure by opportunists since people who are refused to get rich may be considered foolish and others are involved in crimes and are not apprehended or punished, the institutions to ensure accountability like the press, judiciary, law enforcement, legislature are not strong enough to do their statutory functions of upholding all managers to the highest degree of accountability, the culture of impunity resulting in no accountability. At the sub causes levels of poor developmental priorities, impunity again resurfaced as political leaders can misappropriate funds without being held accountable and the fact that politicians are always under immense pressure to satisfy the electoral bases to ensure continued patronage and re-electability.

The effects of all these core problems of POOR FUNDING are: poor learning environments, dilapidated building, ramshackle school furniture, lack of computer and internet facilities to encourage eLearning, lack of potable water to encourage hygiene and fight diseases, demotivated and inefficient teachers compared to well managed high browse private schools, poor academic standards and the resultant poor results in external examinations compared to the private schools that are well managed and the preference of well managed private schools by parents even when their school fees are exorbitant and cannot be afforded by most people.

\subsection{Analysis for Low School Enrolment}

\subsubsection{Fishbone Analysis for Low School Enrolment (Figure 3)}

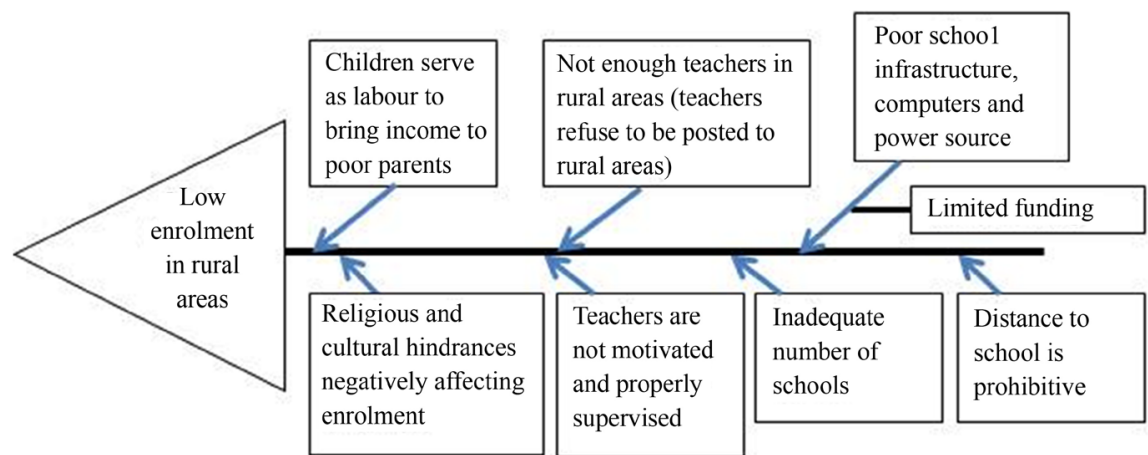

Figure 3. Conceptualized by the researchers.

The fishbone chart above also explained the causes of low school enrolments especially in rural areas. Some of the causes are children of the poor are forced to child labour and often become hawkers of goods on the streets to bring in money for sustenance, which do not only expose the children to road 
hazards but also prevent them from attending school. The other major cause of poor school enrolment is religious and cultural inherences, this especially in the northern parts of Nigeria where Almajiri system is still prevailing and some religious adherents are willing to terrorize people not to go to schools, since many teachers refuse to be posted to the rural areas to teach, the standard of education is lower in the urban areas, it is also a common knowledge that teachers in private schools are better supervised than those in the public schools. Private entrepreneurs are more dedicated to ensuring their students get good results to attract more customers in the future. Again with the increasing population pressures the public schools are over congested and many more cannot be given placements and this forces them to go to expensive private schools are stay out of schools as a result. The poor learning environments is also on its own discouraging people to attend schools and finally especially in the rural areas absence of schools in certain communities discourages people to attend schools especially with the prevailing insecurities in these communities.

\subsubsection{Problem Tree Analysis for Low School Enrolment (Figure 4)}

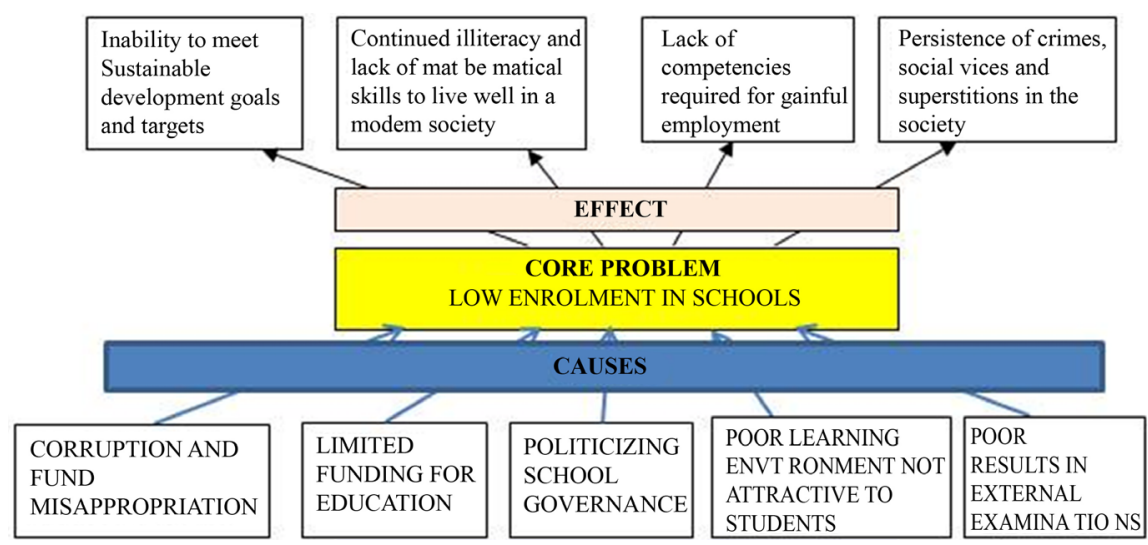

Figure 4. Conceptualized by the researchers.

\subsection{Analysis for Poor Infractructure}

\subsubsection{Fishbone Analysis for Poor Educational Infrastructure (Figure 5)}

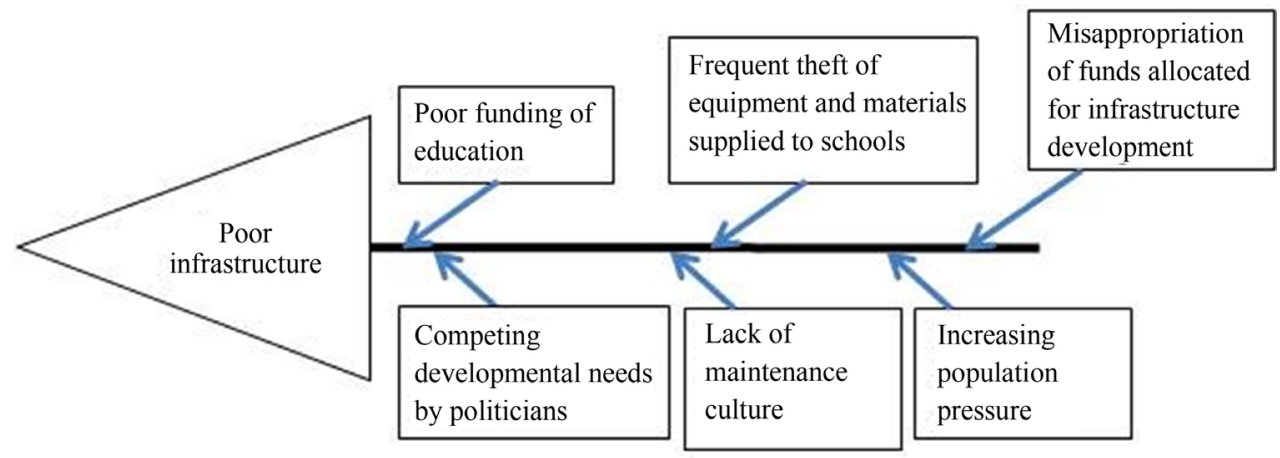

Figure 5. Conceptualized by the researchers. 


\subsubsection{Problem Tree Analysis for Poor Infrastructure (Figure 6)}

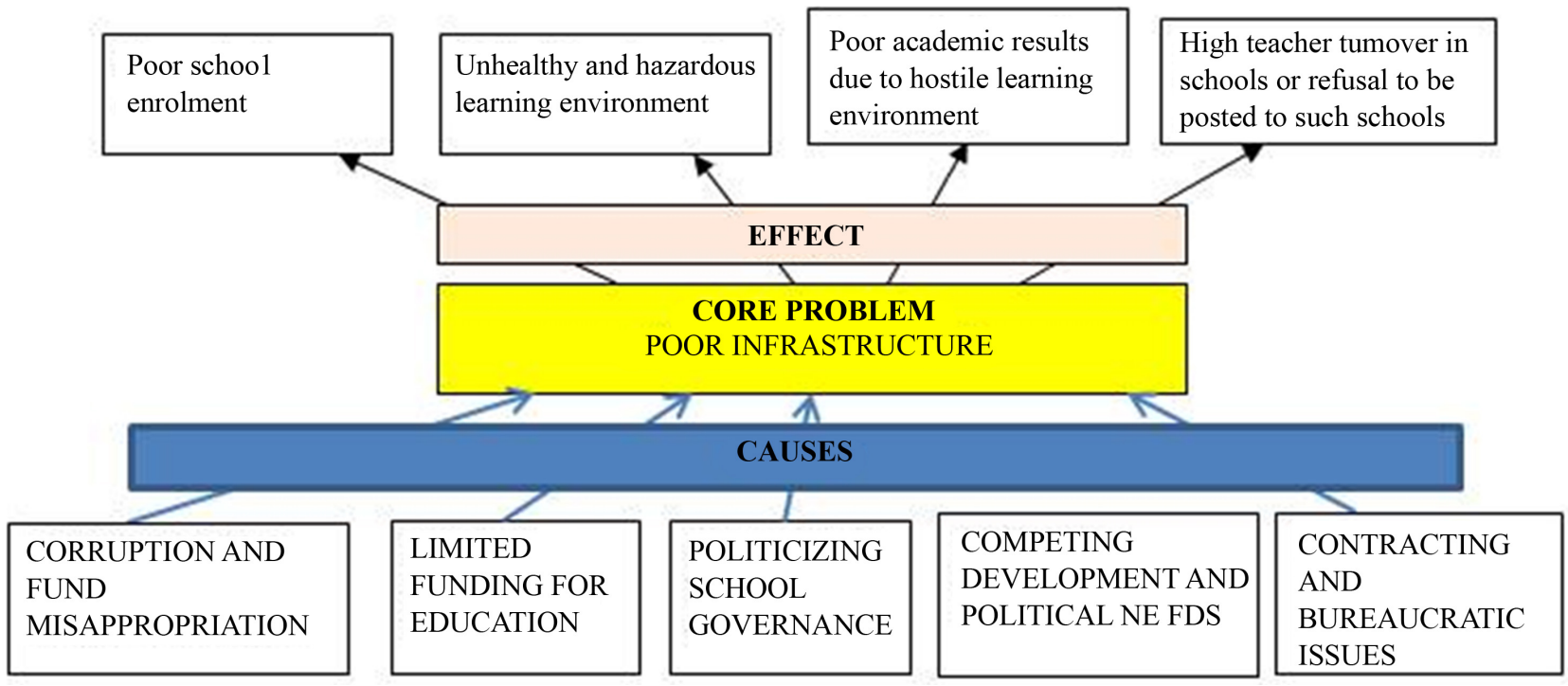

Figure 6. Conceptualized by the researchers.

\section{Discussion}

\subsection{Poor Funding}

\subsubsection{Effects of Poor Funding on the Education Sector}

To a large extent, it is presumed globally that adequate funding of education at all levels determines the quality of the educational system. According to Ekankumo and Kemebaradikumo (2014), poor funding and the mismanagement of funds within the educational system have led to the dysfunctional and unethical practices that have generated limitations across Nigeria's educational system. They further emphasized that poor funding and inadequate implementation of budgetary allocations have led to incidences of the backlog of results, late preparation of results, insufficient staffing, non-availability of most important instructional materials and many more. Agabi (2014) opined that the decay in the education sector is because of inadequate funding of education by Nigeria. Without adequate funding, the much needed eLearning cannot take place. Corona Virus pandemic incidence has aggravated the need for the Ministry of Education to strengthen internet/computer penetration and also build the capacity of the teachers to carry out eTeaching.

Education funding comes from different sources in Nigeria. The major one for all levels of government is public revenue from taxation and proceeds from crude oil (Nwachukwu, 2014). Adesina (1981) stated that the pace at which education had grown in Nigeria particularly since political independence is unparalleled elsewhere among other African countries. The steep increase in the enrolment of students in higher education from 14,468 in 1976 to 176,700 in 1996 (Nwankwo, 1982) is a clear indicator in this regard. However, we know that exponentially increasing population pressure has necessitated the increase in 
enrolment and this has financially stressed most of the governments in the states and at the federal government. In view of that, Nwankwo has tagged education as an expensive social service, requiring adequate financial provision from all tiers of government. Adequate funding of education guarantees staff development through academic programs like workshops, seminars, conferences, and scholarships. Most importantly, staff welfare and retention through regular payment of staff salaries and allowances are assured.

Currently education is grossly under-funded; Nwachukwu (2016) gave a rough estimate of the proportion of the national budget that goes into education from the years 2008 to 2016 in the following percentages: 2008 - 13\%, $2009-8 \%$, 2010 - 6\%, 2011 - 8\%, 2012 - 10\%, 2013 - 8.7\%, 2014 - 10.63\%, 2015 - 9.5\%, 2016 - $8.44 \%$. Other sources of information had equally given the percent allocations for 2017 as 7.4\% (Premium TimesNG, 2019), 2018 as 7.04\% (Premium TimesNG, 2019), 2019 as 7.05\% (PunchNG, 2019: 2020) and 2020 as 6.7\% (Premium TimesNG, 2019).

All the weight of evidence thus points to the fact that the Federal Government is not spending up to the required $20 \%$ of its annual budget on education (Ubogu \& Veronica, 2018). All the percentage allocations for all the years are less than the United Nations Education, Scientific and Cultural Organization's recommendations for developing countries to spend nationally on education whether you use the $26 \%$ benchmark or the more liberal $15 \%$ to $20 \%$ mark.

According to the World Bank (2015), Nigeria's spending as a percentage of its GDP in 2015 was $5.94 \%$. This compares poorly with countries like Ethiopia 9.01, India 10.32, USA 14.44 and UK 19.38. The underfunding persists till today and what we thus are witnessing are the effects of underfunding at all levels. Worse still, allocated budgets are not always appropriated for a number of political and ill-motivated reasons. Even when appropriated, these funds have not always been appropriately utilized.

\subsubsection{Education Misappropriation}

Related to poor funding is the appropriation of funds for education. It is the action of allocating money for the education system at all levels. In other words, it is the sum of money appropriated officially by legislation for a particular use within the education industry of any nation. Funds appropriation includes grant, endowment, or budgeting of money through legislation for some specific reason. It is important to note that no public money can be expended without legislative approval (Ololube 2016). When funds are appropriately approved by the legislatures, the abuse and mismanagement of it are what is known as misappropriation. Misappropriation is a deliberate or illegal use of funds for one's use or other unofficial purposes, particularly by public officials (Mestry, 2004). Mestry further opined that Principals and School Governing Board (SGB) members are usually under great pressure in managing the school's finance with little or no working knowledge, skill and expertise and are usually unable to work out practical solutions to solving the challenges. Due to the recurrent issues of misma- 
nagement of funds through misappropriation, fraud, funds pilfering and many more, principals and SGBs have been subjected to forensic audits by the provincial Department of Basic Education (Rangongo et al., 2016).

Transparency International (2013) explained that corruption at the school level was a global challenge. Supported by Okon, Akpan and Ukpong's (2011) study, that discovered, the lack of proper financial control measures provided opportunities for consistent funds misappropriation within secondary schools. The push in the cost of higher education is a result of the uncontrolled enrollments and desire for education and Nigeria was and has not been strategically positioned to handle the situation according to Ololube, Aiya, Uriah and Ololube (2016). Given all the foregoing, it is not surprising that comments on education and its governance in Nigeria have consistently remained negative. Nwankwo \& Nweke (2016) describe the educational system as a corrupt sector saddled and ridden with vices such as misappropriation of the budget al.located for education, cronyism, the abundance of ghost workers among others, vices that make it difficult for the education system to achieve set goals. The prevalence of gross misappropriation has meant that educational goals are never realized and puts a big question mark over the possibility of the attainment of the lofty goals of SDG4. Other instances of dysfunction abound, and these include the appointment of unqualified teachers, poor supervision, non-provision of instructional resources, etc. (Nwaokugha \& Ezeugwu, 2017). The net outcome of all these is the absence of quality inputs, absence of vital instructional resources, non-conducive learning environments, no libraries, no flip charts, poorly equipped labs, all leading to a situation of poor quality outcomes worsening a bad situation of limited enrolments. Nigeria thus appears to be showing signs that it may not be able to deliver on SDG4 either in terms of numbers or quality learning outcomes.

\subsection{Low School Enrolment}

United Nations (2019) indicates that nearly one fifth of the global population of pupils and students are out of school. The reported noted that in 2017 for every 100 boys that are out of school 121 girls are out of school in sub-Sahara Africa. In Nigeria, it stated that the key challenge facing Nigeria is Out-Of-School-Children. The problem is more pronounced in the northern part of Nigeria where a combination of Almajiri culture and insecurity is making many children to stay out of school. This the major cause of the statistical information of $78 \%$ of children in the South West having the ability to read while only about $17 \%$ of children in the North East can achieve read. Low school enrolment, poor parents sending the children to hawk wares on the streets to bring in income instead of attending schools, the fundamental religious people that would discourage people especially children from attending schools through the application of terrorists strategies including kidnapping and killing and the pervasive refugee situation, poorly maintained and equipped learning environments all are contributing to 
this low enrolment in schools.

\subsection{Poor Infrastructure in Schools}

As noted above, the poor funding of schools is the major reason there is poor infrastructure in schools. School buildings, furniture and equipment are all in bad shapes. While the population of the nation is increasing exponentially, we are not providing education facilities to meet this pressing need. Poor funding is affecting many of the several challenges listed here including low enrolment and poor infrastructure. Also poor funding is affecting other challenges as will be seen in the descriptive assessment. For poor infrastructure, the key cause is political preferences with regards to competing development needs. Government may look at choices like construction of roads, provision of electricity, fighting insecurity, etc. Over funding education despite the fact that human capital is very important to achieving real development. The government along with the school management may also allow provided items to deteriorate without adequate maintenance, in places where there is lack of adequate security, these same items may be stolen.

\subsection{Qualitative Description of the Constraints Militating against Achieving the SDG4/Bottleneck Analysis}

\subsubsection{SDG4 and the Targets (Figure $7 \&$ Figure 8)}

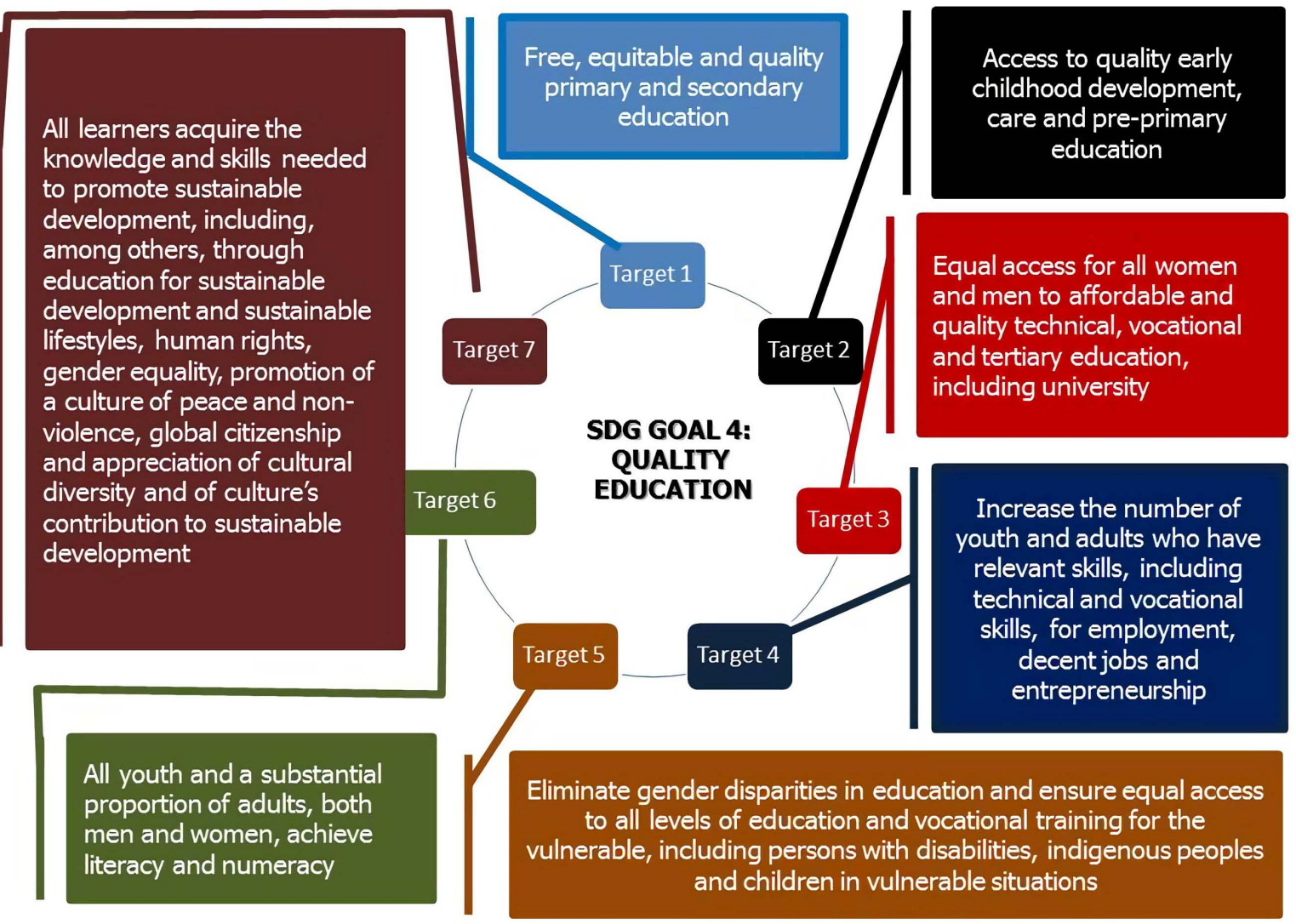

Figure 7. Conceptualized by the researchers. A diagrammatic elucidation of the 7 SDG 4 targets. 


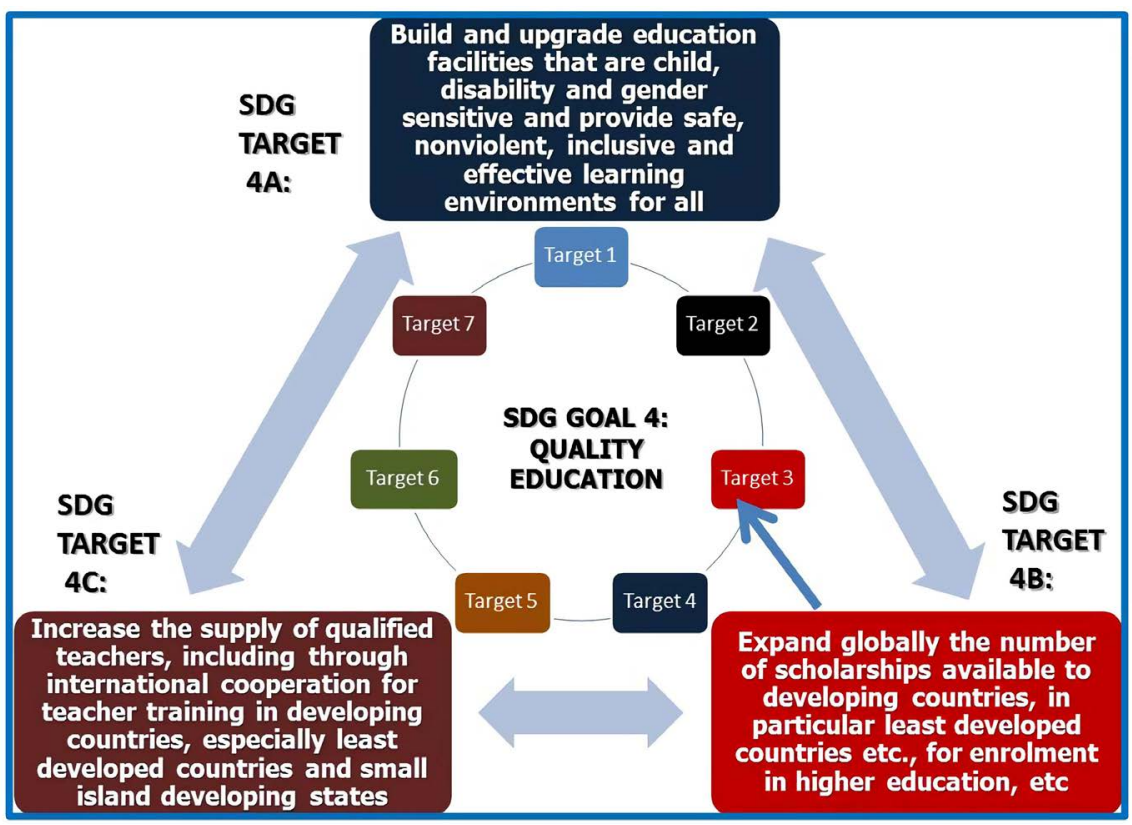

Figure 8. Conceptualized by the researchers. A diagrammatic elucidation of the 7 SDG 4 in relations to the remaining 3 enabling targets.

\subsubsection{Qualitative Descriptive Assessment/Introductory Bottleneck Analysis}

Table 1 shows a descriptive assessment as qualitative analysis by the team to identify the key challenges facing Nigeria from achieving the SDG4:

Table 1. Showing some key challenges militating against achieving SDG4 targets in Nigeria.

- In most states, in Nigeria, primary and secondary education is not free. There is often one levy or the other being paid.

- In the northern parts of Nigeria, many children are out of school because of the persisting Almajiri caste system.

- Many who were in schools in some parts of the north have been displaced from their homes as a result of the terrorist attacks by Boko Haram and alleged herdsmen. They are now refugees as internally displaced people suffering one of the harshest forms of existence.

- Nigeria has one of the highest rates of school children in the whole of the continent of Africa. With a total of 10.2 million out of school children, Nigeria is next to India in this league of poor performing

4.1 By 2030, ensure that all girls and boys complete free, equitable and quality primary and secondary education leading to relevant and Goal-4 effective learning outcomes nations. This sad state of things is caused by a conspiracy of neglect, poor funding, attitudinal reasons, ineffectual implementation and institutional weaknesses.

- Since schooling involves financial expenditures; children from poor people sell on the streets rather than attend schools.

- Over the years, there is an improvement in reducing the distinct disparity of school attendance disfavouring the girl child in the southern part of Nigeria; however, this trend may still exist in the far north.

- The school feeding system which is supposed to encourage pupils from the poor to attend schools is not operational in many states of Nigeria and where they are being operated; it is froth with many challenges. This programme would not have only improved school attendance but also improve the diets of the children from poor homes who would have been assured of at least one good balanced meal per day.

- The assessment by the UN that $88 \%$ of Sub Sahara African children cannot read is very likely since these factors stated above and others are militating against regular primary and secondary level school attendance. 


\section{Continued}

- Attendance of school at the pre-primary education level is improving in Nigeria especially in the urban areas. This is because of the existence of private schools that provide the service. Most states do not have and do not provide pre-primary school facilities. The Education Ministry only supervises these private schools.

- Since private schools are driven by the need to make profit, the school fees are high and many persons in

4.2 By 2030, ensure that all girls and boys have access to quality early childhood development, care and pre-primary education so that they are ready for primary education

the lower-income class and people without any steady means of livelihoods cannot send their wards to such schools.

- Pre-primary schooling is equally non-existent in the rural areas since private persons will not establish schools in areas they will not get a critical number of persons to enable them to make profit from the business.

- The Almajiri caste system and some religious adherents are proving a stumbling block to the government and others providing qualitative education in some parts of the north.

- The assessment by UN in 2017 that only about $42 \%$ of children participate in organised learning one year before the official entry age for a primary school in Sub Sahara African may still be overambitious for Nigeria in the year 2020 since most children of the poor in the urban areas and people in the rural areas do not benefit from it.

- The number of women that attend higher education in Nigeria has improved and in some cases, more women compared to men attend these technical, vocational institutions to acquire skills and other tertiary educational institutions including universities.

4.3 By 2030, ensure equal access for all women and men to affordable and quality technical, vocational and tertiary education, including university

- The Nigerian government has established many federal universities and the government has given licenses to many private concerns who have also established universities. However, funding of universities (mainly public ones owned by states and the federal governments) has continued to be a challenge and when that improves, the quality of university education will improve. Even at this level, however, due to the high human population and poor economic growth of Nigeria, the country has not been able to accommodate adequately everyone willing to attend technical, vocational and tertiary institutions of learning.

4.4 By 2030, substantially increase the number of youth and adults who have relevant skills, including technical and vocational skills, for employment, decent jobs and entrepreneurship

- Most youths and adults do not have skills that would enable them to get employment or become entrepreneurs. This is one of the reasons why unemployment is very high in Nigeria. The government and other private concerns have only been scratching the surface and no significant impact has been achieved.

- There is a huge unemployment problem in Nigeria and the high human population can be a huge market and a fertile ground for entrepreneurs.

- The level of gender disparity is not high in the southern parts of Nigeria because it has been reducing over the years but it is still evident in the northern part of the nation.

4.5 By 2030, eliminate gender disparities in - The kidnapping of many girls from time to time from their schools by Boko Haram and other terrorists has education and ensure equal access to all levels of education and vocational training for the vulnerable, including persons with disabilities, indigenous peoples and children in vulnerable situations discouraged parents from sending their female wards to secondary schools

- The presence of vocational training is not adequate for the able-bodied and the disabled desiring to be trained.

- There is no special attention or affirmative activities benefiting people with disabilities in many states of Nigeria.

- Girls, especially from poor homes, are likely to suffer disruption of their schooling because of teenage pregnancies.

4.6 By 2030, ensure that all youth and a substantial proportion of adults, both men and women, achieve literacy and numeracy
- There is no marked effort to encourage adult education in Nigeria. Many adults are still unable to read and write. The government has not given this aspect of education any good attention.

- The assessment by the UN that $44 \%$ of adults in Sub Saharan Africa are illiterate is realistic.

- There is still massive illiteracy and ignorance militating against people willing to accept the benefits from information derived from educational campaigns for hygiene, disease prevention, sustainable livelihood lifestyles, etc.

- There is also a high level of superstitious beliefs in many communities, giving people false hope and protection against diseases and accidents. These attitudes have detrimentally emboldened many to reject and thereby expose themselves to hazards.

4.7 By 2030, ensure that all learners acquire the knowledge and skills needed to promote sustainable development, including, among others, through education for sustainable development and sustainable lifestyles, human rights, gender equality, promotion of a culture of peace and non-violence, global citizenship and appreciation of cultural diversity and culture's contribution to sustainable development
- Since state and federal governments are grappling with the basic educational issues, they have not commenced sponsorship and promotion of sustainable development education. Civil societies and private concerns under their corporate social responsibility efforts have been more active in this regard than the government. However, Government has played a big and significant role in the education to prevent Corona Virus pandemic.

- There is massive water and air pollution as a result of oil exploration in the Niger Delta and there are no educational efforts to mitigate these and other problems.

- There have been no concerted educational efforts to mitigate the desert encroachment threats in the north most parts of Nigeria.

- There are no efforts to sponsor, promote and educate the communities on sustainable lifestyles, human rights, gender equality, peaceful coexistence, etc. as efforts towards improving the quality of lives of the people of Nigeria. 


\section{Continued}

4.A Build and upgrade education facilities that are child, disability and gender sensitive and provide safe, non-violent, inclusive and effective learning environments for all
- The level of funding for education and other human capital development activities is far below expectations. Most governments prefer spending on roads and other infrastructure because of the palpable lack of social amenities and since the human capital needs mainly impact people who are not in government, political leaders tend to take care of needs that directly affect them.

- The education for people with disabilities is at its rudimentary levels.

- After prolonged neglect by successive governments, most schools or other learning environments, in many state-sponsored schools are in very bad shape. Few states seem to be upgrading the primary and secondary schools gradually with support from the Federal Government counterpart funding schemes but the enormity of the work at hand is daunting. School environments are largely in shambles, no water facilities for potable drinking water or water for sanitation including use in water enabled toilet facilities.

- The pupils/students and computer ratio are unrealistically high and in most instances, computer facilities are non-existent. Internet facilities and computer literacy are more or less non-existent or at rudimentary stages.

- Many states in Nigeria were awarding scholarships to their indigenes to attend higher institutions for over thirty years. This has stopped in many states. The states instead adopted to provide smaller amounts in the form of bursary allowances to their indigenes in higher educational institutions; however, that too has stopped in most states.

- Some scholarship programmes still exist at the federal government level and from some of its agencies. Equally, the private organizations as part of their corporate social responsibility efforts also award a scholarship to deserving beneficiaries after a rigorous selection process. These scholarship schemes are few and are targeted mainly engineering and related disciplines that will benefit the sponsoring organizations concerned.

- Children of the poor do not benefit from these scholarships schemes because they are not able to perform well in the qualification examinations considering their poor educational background and low quality schools they were exposed to and yet their parents cannot afford to pay for them to attend fee paying higher institutions.

- Tuition-free primary and secondary education would have served as some form of scholarship schemes replacement intervention if they are well implemented.

- There are many adverts for scholarship to benefit candidates from developing nations by many universities in western nations and developed countries but results of the outcome of such exercises are not known and the nations that benefited are not known. These efforts in line with the SDG target $4 \mathrm{~B}$ will go a long way towards achieving this target and contributing in a great way towards the achievement of SDG4.

- Scholarship schemes from developed nations to beneficiaries in the developing nations are reducing over time as it seems to us that these nations are beginning to look inward attending to their own pressing needs. The situation of lack of scholarship to benefit deserving candidates in comparison to the massive population of the nation is pathetic in Nigeria.

- The number of teacher training schools and the number of teachers trained has not increased over many years in Nigeria, meanwhile, the population growth is increasing more or less exponentially. The observation is that many former government-owned teacher training colleges have closed.

- However, those already teaching avail themselves to sandwich classes to build their capacities on the job.

- In many states of Nigeria, there are prolonged and persisting employment embargoes by the government and this is also affecting the employment of teachers. There are therefore no efforts to train more teachers and those who are trained are not employed. Many states have not employed teachers for the past several years. Meanwhile, the pupils/students per teacher ratio are increasing with the galloping population pressure and many classrooms have an unmanageable population in primary and secondary schools and even in the public and federal universities.

- Teachers are not motivated with attractive salaries and those who teach do so as the last available option.

\section{Conclusion}

The beauty and functionality of the approach we have adopted in this study are that all the tools lend themselves to easy participatory use by teachers and other 
stakeholders and can be used in problem analysis, root problem identification, potential solution selection and problem resolution sequencing. However, future studies in analyzing challenges in SDGs can in addition to these tools employ incorporate bottleneck analysis especially if identified interventions are being assessed.

For example, our analysis has shown that stopping at underfunding is unsatisfactory since it fails to bring up other issues that operate under the nexus of that heading, factors that influence it and the effects that it also produces. Previous analysis had revealed the following as being major challenges: poor funding, inadequate infrastructure, low enrolment, poor planning. But few studies had tried to show the interactions neither between causes and effects nor of their interactions. What our combination of a problem tree and fishbone analyses have shown is that while underfunding could be a cause, it could also be the effect of deeper social and underlying cause such as lack of fiscal discipline, poor budget planning capacity, corruption, faulty intersectoral and intra-sectoral budget splits, for example. An approach that brings up such intricacies and interrelationships is therefore not only useful but necessary.

The SDG targets were designed to be implemented between 2015 and 2030. That means already 5 years or $33 \%$ of the policy timeframe has been utilized. However, Nigeria is still grappling with how to make significant successes in implementing the goals. Our analysis has revealed that issues like poor funding of education, lack of incentives for children of the poor/parental poverty to enhance school enrolment (one incentive can be the mass adoption of the home grown school feeding programme), poor learning environment as a result of poor funding and mismanagement of funds (causing poor availability of funds for education), location (urban/rural), rejection of western education by some religious groups which have led to the spawning of a large Almajiri population and increase the Nigerian burden of illiteracy, continuing security challenges especially in the northern parts of Nigeria will all contribute to frustrating the attainment of SDG 4 and thereby continue to constitute as challenge for SDG 4.

From the descriptive assessment of the challenges towards achieving SDG 4 Quality Education as explained in Table 1 of this paper, it is not only a problem that not much has been achieved in the last 5 years that is the issue, it is likely that if the game plan is not changed radically by the state and federal governments in the nation, nothing significant would be achieved at the expiration of the SDG implementation term by the year 2030. The exponentially increasing population pressure and the continuous devaluation of the currency will make nonsense of any little progress that is made towards achieving the individual targets.

The challenges enumerated for Nigeria in achieving the SDG 4 in this paper are enormous, however most of these problems will be better managed if adequate funding is given to the education sector and effective fund management system is put in place to prevent misappropriation. Nigeria should therefore have a guiding principle for funding education and that should be providing a 
substantial portion of available fund in the budget to support educational development so as to achieve some meaningful SDG 4 implementation progress. This should go along with the need to strengthen our institutions so that corruption and impunity can be better controlled, there is the need for the populace to demand greater funding for education from our political leaders, there should be proper use of the education tax levied people, there should be better supervision and motivation of teachers especially those posted to the rural areas. Government should devise ways of reducing overcrowding in schools especially now that the need for social/physical/safety distancing is required to reduce spread of diseases and reduce their impacts on the populace. This can take the form of every public school now having morning and afternoon sessions as school 1 and School 2 but managed by the same set of teachers, school workers and school managers to reduce costs. This also means that the workload of all working in public schools (teachers, non-academic staff and school managers) will increase necessitating giving the workers increased incentives for the extra work they have to do. We also need to improve the learning environments, install computers/internet facilities, secure all provided school equipment and construct bore hole-water systems and public toilets in every school and in the process make schools safe, habitable and good places to learn. Very importantly since the issue of out-of-school-children remains a major challenge, government must quickly introduce the home grown school feeding programme in every public primary school to encourage children to attend school and improve school enrolment. Equally the intervention will help provide a balanced diet every school day to these pupils, which will invariably improve their health and related needs.

Towards this end, Nigeria will need to address observed weaknesses in public expenditure management which according to the World Bank (1998) continue to plague developing economies if it is to make progress in addressing SDG4 in particular and all the other SDGs. These weaknesses include poor planning, poor expenditure control, inadequate funding, the little relationship between planned and actual expenditure, inadequate reporting, poor checks and balances, and too much input-based budgeting at the expense of results-based budgeting.

\section{Acknowledgements}

We thank Mr. Dango Wakwe Lawrence (Manager, CIRCI) and Mr. Owanari Chukwuma Lawrence for the editorial support given.

\section{Conflicts of Interest}

The authors declare no conflicts of interest regarding the publication of this paper.

\section{References}

Adesina, S. (1981). What Is Educational Planning? Introduction to Educational Planning. Ili-Ife: University of Ife Press.

Agabi, C. O. (2014). Teaching and Resources Management in Education. Port Harcourt: 
Rodi Printing and Publishing.

Allen, C., Metternicht, G. \& Wiedmann, T. (2018). Initial Progress in Implementing the Sustainable Development Goals (SDGs): A Review of Evidence from Countries. Sustainability Science, 13, 1453-1467. https://doi.org/10.1007/s11625-018-0572-3

Coccia, M. (2017). The Fishbone Diagram to Identify, Systematize and Analyze the Sources of General Purpose Technologies. Journal of Social and Administrative Sciences, 4, 1-14.

Coccia, M. (2018). The Fishbone Diagram to Identify, Systematize and Analyze the Sources of General Purpose Technologies. Journal of Social and Administrative Sciences, 4, 291-303. https://ssrn.com/abstract=3100011

Ekankumo, B., \& Kemebaradikumo, N. (2014). Quality Financing of Higher Education in Nigeria: A Nostrum for the Provision of Quality Education. Journal of Education and Practice, 5, 78-90.

García-Feijoo, M., Eizaguirre, A., \& Rica-Aspiunza, A. (2020). Systematic Review of Sustainable-Development-Goal Deployment in Business Schools. Sustainability, 12, 440. http://www.mdpi.com/journal/sustainability https://doi.org/10.3390/su12010440

Ishikawa, K. (1990). Introduction to Quality Control. Tokyo: 3A Corporation.

Marinho, H. (2002). Tools and Techniques for Mobilizing Resources for Schools. The Forum on Cost and Financing of Education in Nigeria, Education Sector Analysis (ESA), Abuja, 17-19 September 2002.

Mestry, R. (2004). Financial Accountability: The Principal or the School Governing Body? South African Journal of Education, 24, 126-132.

Nwachukwu, P. O. (2014). Funding Education for Sustainable Development in Nigeria: Challenges and the Way Forward. Journal of Education and Practice, 5, 51.

Nwankwo, B.C. \& Nweke, P.O. (2016). Effect of Corruption on the Educational System: A Focus on Private Secondary Schools in Nsukka Zone, Nigeria. Global Journal of $\mathrm{Hu}$ man-Social Science, 16, 59-67.

Nwankwo, J. I. (1982). Educational Administration: Theory and Practice. New Delhi: Viklas.

Nwaokugha, D. O., \& Ezeugwu, M. C. (2017). Corruption in the Education Industry in Nigeria: Implications for National Development. European Journal of training and Development Studies, 4, 1-17.

Okon, F. I., Akpan, E. O., \& Ukpong, O. U. (2011). Financial Control Measures and Enhancement of Principals' Administrative Effectiveness in Secondary Schools in Akwa Ibom State. African Journal of Scientific Research, 7, 335-342. http://www.journalsbank.com/ajsr 7 1.pdf

Ololube, N. P. (2016). Education Fund Misappropriation and Mismanagement and the Provision of Quality Higher Education in Nigeria. International Journal of Scientific Research in Education, 9, 333-349. http://www.ijsre.com

Ololube, N. P., Aiya, F., Uriah, O. A., \& Ololube, D. O. (2016). Strategic Planning: A Universal Remedy for the Successful Management of 21st-Century University Education (UE). Management, 6, 76-88.

Premium TimesNG (2019). Budget 2020: Buhari Proposes N48 Billion for Capital EXpenditure in Education. https://www.premiumtimesng.com/news/top-news/356794-budget-2020-buhari-propo ses-n48-billion-for-capital-expenditure-in-education.html

Preuss, P. G. (2003). School Leader's Guide to Root Cause Analysis: Using Data to Dissolve Problems. Larchmont, NY: Eye on Education. 
PunchNG (2019). 2019 Budget: Education Gets N620.5bn, against UNESCO's Advice. https://punchng.com/2019-budget-education-gets-n620-5bn-against-unescos-advice/

Rangongo, P, Mohlakwana, M, \& Beckmann, J. (2016). Causes of Financial Mismanagement in South African Public Schools: The Views of Role Players. South African Journal of Education, 36, 1-10. https://doi.org/10.15700/saje.v36n3a1266

San, G. S., Tjitro, S., \& Santoso, M. (2003). Desain Eksperimen untuk Mengoptimalkan Proses Pengecoran Saluran Keluar Teko. Journal Teknik Meisin, 5, 5-10. http://www.academia.edu/1071634/

Schiefer, U., \& Döbel, R. (2001). MAPA-PROJECT. A Practical Guide to Integrated Project Planning and Evaluation. Budapest: OSI. http://www.kec-ks.org/botimet/MAPA-english.pdf

Start, D., \& Hovland, I. (2004). Tools for Policy Impact: A Handbook for Researchers. London: Overseas Development Institute.

http://www.odi.org.uk/Rapid/Publications/Documents/Tools handbook final web.pdf

Tiann (2012). Diagram Fishbone Dari Ishikawa. https://tianno.wordpress.com/2012/05/

Transparency International (2013). Daily Lives and Corruption: Public Opinion in Luxembourg. Global Corruption Barometer. Berlin: Transparency International. http://www.transparency.lu/wp-content/uploads/2013/07/Luxembourg-GCB-2013-cou ntry-report-9.7.2013.pdf

UBEC (2019). 2018 National Personnel Audit (NPA) Report on Public and Private Basic Education Schools in Nigeria. Abuja: Binani Printing Press.

Ubogu, R. E., \& Veronica, M. O. (2018). Financing Education in Nigeria: Implications and Options for National Development. World Journal of Educational Research, 5, 227-235. https://doi.org/10.22158/wjer.v5n3p227

UNICEF Nigeria (2019). https://www.unicef.org/nigeria/education

United Nations (2019). Sustainable Development Goal Report 2019.

Veselý, A. (2008) Problem Tree: A Problem Structuring Heuristic. Central European Journal of Public Policy, 2, 68-81.

Weiss, W., Bolton, P., \& Shakar, A. (2000). Rapid Assessment Procedures (RAP): Addressing the Perceived Needs of Refugees and Internally Displaced Persons through Participatory Learning and Action. Baltimore, MD: CERTI and USAID. http://www.certi.org/publications/Manuals/rap-16 section3.pdf

World Bank (1998). Public Expenditure Management Handbook. Washington DC: World Bank. https://doi.org/10.1596/0-8213-4297-5

World Bank (2015). http://www.thrglobaleconomy.com/rankings/Government

Worldmeters (2019).

https://www.worldometers.info/world-population/nigeria-population/ 